\title{
Factors Influencing Utilization of Pediatric Eye Care Services in Bangladesh: A Qualitative Study
}

\author{
Nahid Ferdausi ${ }^{1 *}$, Jarin Tasnim Khan ${ }^{2}$ and Tausif Akib Khan ${ }^{3}$ \\ ${ }^{1}$ Associate Professor (Ophthalmology), National Institute of Ophthalmology and \\ Hospital, Dhaka, Bangladesh \\ ${ }^{2}$ General Secretary, KHEA Foundation, Dhaka, Bangladesh \\ ${ }^{3}$ President, KHEA Foundation, Dhaka, Bangladesh \\ *Corresponding Author: Nahid Ferdausi, Associate Professor (Ophthalmology), \\ Low Vision Department, National Institute of Ophthalmology and Hospital, Dhaka, \\ Bangladesh.
}

Received: March 22, 2021

Published: April 23, 2021

(C) All rights are reserved by Nahid Ferdausi., et al.

\begin{abstract}
Background: Visual impairment and blindness in children can be devastating if not addressed timely. The impact of unmet pediatric eye care needs in Bangladesh is compounded by barriers to accessing eye care, limited engagement with communities, lack of awareness of parents and caregivers, poor health-seeking behavior, lack of an organized system of case findings, lack of appropriate referral network, and affordability. The purpose of this study was to elucidate factors that influence, positively or negatively, people's willingness to seek and utilize pediatric eye care services.

Methods: A qualitative study was conducted to have an in-depth understanding of the utilization of current pediatric eye care services in Bangladesh. In-Depth-Interviews (IDIs) and Focus Group discussions (FGDs) were used for data collection. Twenty IDIs were completed among policymakers, eye care managers, and service providers. Four FGDs were carried out among parents who attended eye care management in the public hospital and private chamber. Two FGDs were conducted among schoolteachers during school sight testing programs. Thematic analysis carried out.

Results: This study identified several interconnected barriers and enablers that affect the utilization of pediatric eye care services. Several factors like non-availability, poor accessibility of services, non-affordability, poor knowledge of available services have been identified that prevent parents from using pediatric eye care services for their children. Lack of knowledge and information about timely intervention of eye diseases recognized as major barrier. There is an urgent need for involving all key stakeholders to create a greater impact in reducing the burden of childhood blindness.

Conclusion: Early detection and management of eye diseases will reduce the burden of visual impairment and disability. Utilization of available eye care services is necessary for the reduction of the burden of visual impairment. Awareness campaigns on available pediatric eye health care services, especially amongst those who live in the rural and remote areas are essential.
\end{abstract}

Keywords: Factors; pediatric eye care utilization; Bangladesh

\section{Background}

The prevalence of blindness in children is closely related to economic development and the social determinants of health. It var- ies from place to place and ranges from an estimate of $0.3 / 1000$ children in countries with high income to $1.5 / 1000$ children in low -income countries with a global figure estimated at 0.7/1000 [1-3]. 
Analysis of global epidemiological data on the pattern of blindness indicates that up to $75 \%$ of the causes are avoidable. Avoidable blindness is defined as blindness, which could be either treated or prevented by known, cost-effective means [4].

It is reported that reducing visual loss in children poses challenges because there is an urgency about treating childhood eye diseases as delay may lead to amblyopia. In addition, the assessment of vision and examination of the children's eyes also pose particular difficulties, which require time and experience on the part of the examiner [5]. Prevention of avoidable visual impairment leads to substantial long-term savings in public health-care and social expenditures, in proportion to the number of individuals who no longer need medical or social assistance. Savings also occur from the significantly reduced commitment made by family members caring for a visually impaired person $[4,6]$.

According to the Bangladesh Childhood blindness study 2003, it was estimated that there were about 40000 blind children in Bangladesh by using under-5 mortality rates and blindness prevalence estimates in children [7]. The household-level survey employed in 2017 in a rural community of Bangladesh, in which the prevalence of childhood blindness was estimated. According to that study, the prevalence rate of childhood blindness was 6.3 per 10,000 children. Through the extrapolation of this number to the national target group, it was found that around 35,000 children in Bangladesh are currently living with blindness [8].

Utilization of health facilities can be influenced by various factors including: availability, acceptability, and accessibility of services; the individual's illness behavior; perception of threat to life and function; and the attractiveness of the value gained by using available health facilities [9-13]. Andersen's model of healthcare utilization classifies these variables into the following three categories: predisposing factors, enabling factors, and need factors $[14,15]$. They work together to impact the probability that a person would utilize healthcare services. Predisposing factors are present before an illness and refer to an individual's tendency to utilize healthcare services irrespective of whether the services are required. Enabling factors are related to the surrounding circumstances that affect an individual's ability to utilize healthcare services. While a need factor is either the presence of ill-health or the perception of need. A noted change in function or a disability is an example. Need factors may be considered to be more important as they are the immediate determinants of service utilization. Thus, in the presence of predisposing and enabling factors, a need for the healthcare service is required for utilization to actually take place. Eye care service utilization is equally influenced by the factors that affect the utilization of health services in general. Several studies have been conducted to better understand the factors that affect the uptake of eye care services [16-18].

Three main reasons for the high prevalence of visual impairment are non-availability; non-accessibility and non-affordability of eye care services [19]. However, there several factors act as bottlenecks to take advantage of available, accessible and affordable eye care services. Lack of knowledge of available services, unawareness of the possible impact of eye disease, and not fully cognizant of whom to consult for management of eye diseases are the three major causes. Also, demographic, personal, social and cultural factors influence or act as barriers to eye care utilization [19]. Awareness raising programs will lead to better understanding and promote greater utilization of eye care services where utilization of available services is poor.

Early detection and management of eye diseases will reduce the burden of visual impairment and disability. Therefore, eye care providers and health care managers must have a deep understanding of various factors that influence negatively the utilization of eye care services and be responsive to them [19]. It is important for eye care managers and providers to be conversant with the various barriers to the utilization of eye care services and prevent them. The utilization of available eye care services is mandatory for the reduction of the burden of visual impairment worldwide. It is essential that utilization is monitored and barrier factors are eliminated by relevant sectors. This study focused to elucidate factors that influence, positively or negatively, people's willingness to seek and obtain eye care services.

\section{Methods}

This study adopted a qualitative narrative research design. An in-depth, qualitative research approach is used to examine perceptions of what influences people to receive pediatric eye care services. In-depth interviews (IDIs) and focus group discussions (FGDs) were the research methods. Total six FGDs conducted among parents and teachers. Twenty IDIs were conducted among policy- 
makers, eye care managers, and service providers. This study was conducted during the period of January 2019 to December 2019. Two FGDs were carried out among parents who attended their children's eye care services in the public hospital, and two at the private chamber. Two FGDs were conducted among teachers in school sight testing programs (SSTP).

The focus groups had an average of 10 participants per group (range 9 to 11). The mean age of the participants attended in FGDs 31 years (range 25 to 45 years) Participants' educational level was from illiterate to Masters.

Focus groups convened to examine the complex way in which perception and knowledge influence behaviors related to seeking pediatric eye care services. A series of prompts (Table 1) finalized.

\begin{tabular}{|l|c|c|}
\hline $\begin{array}{c}\text { Serial } \\
\text { No }\end{array}$ & Area of discussion & Prompts used \\
\hline 1 & $\begin{array}{c}\text { Perception and awareness of } \\
\text { common childhood blinding } \\
\text { eye conditions }\end{array}$ & $\begin{array}{c}\text { What, who affected, when } \\
\text { affect, treatment }\end{array}$ \\
\hline 2 & $\begin{array}{c}\text { Knowledge about available } \\
\text { pediatric eye care services }\end{array}$ & $\begin{array}{c}\text { Where, who provide } \\
\text { services, what services are } \\
\text { available }\end{array}$ \\
\hline 3 & $\begin{array}{c}\text { Barriers in pediatric eye care } \\
\text { services }\end{array}$ & $\begin{array}{c}\text { Whether available, } \\
\text { accessible, affordable, } \\
\text { service providers } \\
\text { behavior, }\end{array}$ \\
\hline 4 & Actions can be taken & $\begin{array}{c}\text { Community level, } \\
\text { institutional level, policy } \\
\text { level }\end{array}$ \\
\hline
\end{tabular}

Table 1: Prompts for discussion.

A structured thematic guideline was developed to guide discussions. Qualitative interviews conducted using specific interview guides for IDIs and FGDs covering different themes, such as the perception of eye diseases and eye care, previous experience of eye care facilities, perceived and experienced barriers and enablers in accessing eye care services.

The qualitative data audiotaped, transcribed, translated, and coded. Each in-depth interview took approximately thirty minutes and each FGD took around forty-five minutes. The Bengali transcription was translated into English. The main response is catego- rized to its theme. The main responses from the respondents were reported using narrative and quoted verbatim.

Thematic analysis was carried out and finally, the narrative qualitative information was organized and integrated according to themes and concepts that were answered in the research questions.

\section{Results}

The main reasons for seeking consultations for pediatric eye care are refractive errors, congenital/developmental cataracts, strabismus, symptoms related to allergy, infection or inflammation, lacrimation, ocular trauma, retinoblastoma, low vision, and other symptoms or conditions. This study identified a number of interconnected barriers and enablers that affect the utilization of pediatric eye care services by parents of children at risk of sight loss. The effect of certain predisposing factors such as parents living in remote areas, low level of education among parents, low empowerment of women, and lack of information has a huge influence on the utilization of pediatric eye care services.

\section{Results of FGDs}

This study found that perceived lack of awareness and lack of need for eye examinations are important factors governing the utilization of pediatric eye care need. Poor understanding and lack of proper information of potentially blinding eye diseases have been reported as barriers to pediatric eye care utilization.

Parents' perception and awareness about pediatric eye diseases

A significant number of the parents mentioned that they were not informed about congenital cataracts before the diagnosis of their child. Even they did not think that a child could suffer from a cataract. It was very frustrating when they tried to get access to the specialists. These findings supported by the following statement: "I am a day laborer. We found that the center of the eye of our only 3-month-old son became white. Friends around us assured us that it would be fine with time. But advised by a health worker, we once had a local doctor take a look. The doctor told us that it was a cataract and suggested us to see a city doctor when the child would become one year old. When he was one year old, we went to District Hospital and they told us to take him to Dhaka for eye surgery. Then we had the surgery done in Dhaka. But the surgeon told that the surgery should have been done as soon as the white pupil was 
detected. It was already late. We could have done the surgery at the right time had we known the correct information even though we were poor".

Good number of participants opined that general physicians should be the 'gatekeepers' of the pediatric eye care utilizations. Participants felt it because they perceived that their physicians were not aware about pediatric eye health care that was related to general health care. One of the participants' accounts was: "My daughter was born prematurely at home; at that time she was treated at Upazila and district level government hospital for her general health. But when she was one and half years we understand that she could not see. Then we visited an eye hospital and then referred to Dhaka. That time consultant told us that her eye problem was due to premature delivery. If I were advised by a general physician for eye examination due to prematurity then it could be early detected".

Teachers' perception and awareness about Pediatric eye diseases

FGD for schoolteachers conducted during school sight testing program. Few teachers stated that they noticed that sometimes students faced difficulties to follow blackboard and they informed their parents. These few teachers believed that they could help their students to receive effective treatment. However, most of the teachers are not aware about the symptoms of defective vision and available services and there are some misconception about child's eye diseases.

\section{Knowledge about availability of pediatric eye care services}

Lack of knowledge of available care has reported as one of the important barriers to pediatric eye care utilization. Knowledge and proper information about available services influenced the uptake of services positively. As knowledge of available eye care services was associated with higher utilization, respondents suggest a need for an awareness campaigns on available health care services, especially amongst those who live in the rural and remote areas. One of the mother's statement was: "My daughter is now 10 years old. Her two eyes not aligned from early childhood. My mother-in-law and other relatives told that this is not a problem at all. In the community, all believes that this eye condition is the symbol of 'good luck'. I did not know that this problem has treatment. I visited an eye hospital for my mother in law's eye problem and my daugh- ter was with us at that time. Doctor look at my daughter's eye and for the first time she told that my daughter was suffering from eye problem and it has treatment. Then my daughter was treated. Now her both eye is aligned and she looks good".

Results of in-depth interviews: Policy makers/program managers/service providers perception

Properly utilized eye-care personnel, adequate facilities, appropriate educational programs, and community involvement have been considered as the hallmarks of pediatric eye care utilization. Availability of pediatric eye care services varies from district to district, even from one community to another. The disproportionate distribution of manpower in ophthalmological services between rural and urban areas influences the service utilization negatively. Poor to non-existing referral channels from primary health care centers to secondary and tertiary care centers have been considered a barrier in sustaining pediatric eye care utilization.

The majority of the respondents feel non-availability is not the only barrier to utilization of pediatric eye care services. It was evident that lack of information about eye diseases was one of the reasons for delaying treatment since pediatric eye care is given a low priority among competing health and non-health needs. The barriers due to lack of understanding about pediatric eye diseases, their management, lack of information about available services, and poor effort to take up services may be related to the behavior that arises from the individuals' and communities' perception.

\section{Suggestions from FGDs}

This study suggests that parents/caregivers are not well informed about eye health, child's eye diseases, or the need for an eye examination. Participants advocate that messages about pediatric eye health and eye care must be conveyed through the media or by the primary health workers on regular basis.

Eye health education and promotion activities are essential for preventing blinding conditions and increasing uptake of services. For the implementation of childhood blindness prevention programs, schools are an effective setting. Vision screening for refractive error correction has been increasingly conducted in schools across the globe. in this study school teachers strongly advocated for eye health promotion campaign through an ophthalmologist's oral presentation; posters displayed at school premises; distribu- 
tion of brochures/leaflets and stickers communicating child's eye health messages; and importance of school vision screening.

\section{Recommendations from IDIS}

It has been suggested that eye health should be included as a major element in broader non-communicable and communicable disease frameworks, as well as those addressing aging and child populations. To address the avoidable childhood blindness there is a need for appropriate coordination between ophthalmologists, pediatricians, and obstetricians for early diagnosis and timely intervention. There is an urgent need to involve community clinics in early case detection, timely referral, and regular follow-up of eye diseases. By connecting community clinics, public awareness and community participation can be enhanced. Health education programs, targeted screening programs and community participation will be extremely beneficial in motivating the people about the benefits of seeking help much earlier.

\section{Discussion}

Eye care service utilization is equally influenced by the factors that affect utilization of health services in general. Several studies have conducted to better understand the factors that affect the uptake of eye care services [20-23]. According to Andersen [14], health care services usage is determined by societal, health service system and individual factors. These various factors such as age, gender, marital status, race/ethnicity, occupation, beliefs (such as attitudes towards health services), knowledge about disease, and values interact to influence the likelihood of an individual's utilizing health care services $[24,25]$. These factors are also applied in case of utilization of pediatric eye care services.

In current study it was found that certain predisposing factors like, girl child, parents living in remote areas, low level of education of parents have huge influence on less utilization of pediatric eye care services. The findings suggest that poor knowledge of child's eye diseases have negative influence. Non-availability of pediatric eye care services in the remote rural areas and lack of knowledge of the available services is associated with limited-service utilization. Schaumberg., et al. [26], Palagyi., et al. [27], Chandrashekar., et al. [28], Bhagwan., et al. [29] and Farmer., et al. [30] have reported that knowledge of available eye care services increased the utilization of eye care services.
The study findings suggest that raising public awareness through community programs can be an effective approach for utilization of eye care services. Fotouhi., et al. [31] are of the opinion that the key factors in achieving the goals of Vision 2020 are eye care services and utilization. These imply that apart from manpower and infrastructure development, community programs are needed to ensure utilization of eye care services.

\section{Conclusion}

The study findings reveal that pediatric eye care services must be available, accessible, and affordable covering all geographical areas of the country. Subsequently, factors that act as barriers to their proper usage must be addressed and provide means to remove them. Planning for pediatric eye care services in rural areas is critical. Adequate publicity, caregivers' good perception, effective eye care team performance and overall good services can create awareness about the need to avail pediatric eye care services. Promotions of available pediatric eye care services must be done intensively and the implications of delayed eye care need to be emphasized. People should aware that most vision problems can correct and blindness can be prevented by seeking eye care services promptly. It is expected that knowledge gained from this study will help in devising policies to overcome the barriers related to eye care service utilization. This will consequently improve the quality and uptake of pediatric eye care services in our environment and similar settings around the world.

\section{Bibliography}

1. Shamanna BR and Muralikrishnan R. "Childhood Cataract: Magnitude, Management". Economics and Impact Community Eye Health Journal 17.50 (2004): 17-18.

2. Gilbert C., et al. "Prevalence of blindness and visual impairment in children: a review of available data". Ophthalmic Epidemiology 6.1 (1999): 73-81.

3. Courtright P., et al. "Childhood cataract in Africa". Community Eye Health Journal 21 (2008): 65.

4. Solange R., et al. "Prevalence and Causes of Visual Impairment in Low-Middle Income School Children in São Paulo, Brazil 16.5 (2002): 557-561. 
5. Gilbert $\mathrm{C}$ and Foster A. "Childhood blindness in the context of Vision 2020-the right to sight". Bull World Health Organization 79 (2001): 22-232.

6. "Global initiative for the elimination of avoidable blindness". Geneva, World Health Organization (1998).

7. Bangladesh Childhood Blindness Study (2003).

8. AHM Enayet Hussain., et al. "Epidemiology of childhood blindness: A community-based study in Bangladesh". PLOS ONE (2019).

9. Bosch D and Busby A. "The five A's of rural home care". Caring 16 (1997): 20-25.

10. Dawodu OA., et al. "Pattern of utilization of eye care services in Benin city, Nigeria". The Nigerian Postgraduate Medical Journal 13 (2006): 323-325.

11. Duggal R. "Health care utilisation in India". Health Millions 2 (1994): 10-12.

12. Kasl SV and Cobb S. "Health behavior, illness behavior, and sick role behavior. I. Health and illness behavior". Archives of Environmental and Occupational Health 12 (1966): 246-266.

13. Okonkwo JE and Ngene JN. "Determinants of poor utilization of orthodox health facilities in a Nigerian rural community". The Nigerian Journal of Clinical Practice 7 (2004): 74-78.

14. Andersen RM. "Revisiting the behavioral model and access to medical care: Does it matter?" Journal of Health and Social Behavior 36 (1995): 1-10.

15. Andersen R and Newman JF. "Societal and individual determinants of medical care utilization in the United States". Milbank Q 51 (1973): 95-124.

16. Brian G., et al. "Eye care in Fiji: A population-based study of use and barriers". Ophthalmic Epidemiology 19 (2012): 43-51.

17. Lee L., et al. "Changing barriers to use of eye care services in Timor-Leste: 2005 to 2010". Ophthalmic Epidemiology 20 (2013): 45-51.

18. Vela C., et al. "Eye care utilization by older adults in low, middle, and high income countries". BMC Ophthalmology 12 (2012): 5.

19. Ntsoane MD and Oduntan OA. "A review of factors influencing the utilization of eye care services". South African Optometrist 69.4 (2010): 182-192.

20. Jin YP and Trope GE. "Eye care utilization in Canada: Disparity in the publicly funded health care system". The Canadian Journal of Ophthalmology 46 (2011): 133-138.

21. Brian G., et al. "Eye care in Fiji: A population-based study of use and barriers". Ophthalmic Epidemiology 19 (2012): 43-51.

22. Lee L., et al. "Changing barriers to use of eye care services in Timor-Leste: 2005 to 2010". Ophthalmic Epidemiology 20 (2013): 45-51.

23. Vela C., et al. "Eye care utilization by older adults in low, middle, and high income countries". BMC Ophthalmology 12 (2012): 5.

24. Bradley E. "Health services research: Expanding the Anderson Model: The role of psychosocial factors in long term care use" (2008).

25. Keeffe JE., et al. "Utilization of eye care services by urban and rural Australia". British Journal of Ophthalmology 86 (2002): 24-27.

26. Schaumberg D., et al. "Demongraphic predictors of eye care utilization among women". Medical Care 38 (2000): 638-646.

27. Palagyi A., et al. "Eye care in Timor-Leste: a population-based study of utilization and barriers". Clinical and Experimental Ophthalmology 36 (2008): 47-53.

28. Chandrashekar TS., et al. "Coverage, Utilization and barriers to cataract surgical services in rural South India, Results from a population based study". Journal of Public Health 121 (2007): 130-136.

29. Bhagwan J., et al. "Knowledge, attitude and practices regarding cataract surgery among severe cataract cases in Hanyana". Indian Journal of Community Medicine 31 (2006): 66-68.

30. Farmer J., et al. "Rural /Urban differences in accounts of patients' initial decision to consult primary care". Health and Place 12 (2006): 210-221. 
31. Fotouhi A., et al. "Eye care utilization patterns in Tehran population: A population based cross-sectional study". British Journal of Ophthalmology 6 (2006): 4-12.

\section{Assets from publication with us}

- Prompt Acknowledgement after receiving the article

- Thorough Double blinded peer review

- Rapid Publication

- Issue of Publication Certificate

- High visibility of your Published work

Website: www.actascientific.com/

Submit Article: www.actascientific.com/submission.php

Email us: editor@actascientific.com

Contact us: +919182824667 